\title{
HIV Sero-Prevalence among Infants Attending Immunization Centers in Calabar Metropolis, Cross River State, Southern, Nigeria
}

\author{
Venn J. Ifeoma*, Ochigbo O. Sunday, Anah U. Maxwell and Asindi A. Asindi
}

Department of Pediatrics, University of Calabar, Calabar, Nigeria

\begin{abstract}
Introduction: Pediatric Human Immunodeficiency Virus (HIV) infection accounts for over $2.3 \%$ of all pediatric infections. Many HIV-infected infants are not identified until they develop symptoms and present with illness at health facilities. However, the six weeks immunization visit provides an opportunity for HIV-infected mothers and their exposed infants to be identified before symptoms occur. This study was therefore conducted to determine the HIV status of infants attending immunization clinics in Calabar with a view to enrolling them into treatment.

Subjects and Method: This cross sectional descriptive study was conducted in two Local Government Areas of Calabar consisting 22 selected immunization centers. Using the multistage sampling method, 330 infants were screened. Ethical clearance was obtained from the supervising Ministry of Health. Rapid test was conducted, reactive specimens had Deoxyribonucleic Acid Polymerase Chain Reaction (DNA PCR) done using Dried Blood Spots (DBS).

Results: A total of 330 infants aged 6 to 14 weeks were recruited, $173(52.4 \%)$ were males while 157(47.6\%) were females giving male to female ratio of $1.1: 1$. Mean age of the infants was $9.20 \pm 3.1$ weeks. Twenty four (24) tested positive for HIV antibodies, after HIV DNA PCR test, 14(4.2\%) infants were infected. Antenatal care registration (ANC) and maternal ANC HIV status were statistically significant $P=0.03$ and $P=0.02$ respectively.

Conclusion: HIV exposed and infected infants are still been missed and only diagnosed later in life. Therefore, maternal HIV status determination and early diagnosis at immunization centers is recommended to bridge the Prevention of Mother To child Transmission (PMTCT) gap.
\end{abstract}

Keywords: DBS, HIV, Infants, DNA PCR, PMTCT, ARV.

\section{INTRODUCTION}

Human Immunodeficiency Virus (HIV) and Acquired Immunodeficiency Disease Syndrome (AIDS) is still a major cause of childhood morbidity and mortality in Africa [1]. Globally, HIV contributed $2 \%$ of under-five mortality by end of 2013 [2] and this figure is on the increase. The National prevalence from 2014 sentinel survey among Antenatal Care (ANC) attendees was $3.4 \%$ [3]. Nigeria carries one of the globes heaviest burdens of HIV. Mother-to-Child Transmission (MTCT) of HIV is the main route of Paediatric HIV infection and accounts for over $90 \%$ of all pediatric infections [3]. The Prevention of Mother-to-Child Transmission (PMTCT) of HIV is the key to reducing pediatric HIVIAIDS. Nigeria contributes $32 \%$ to the world gap in achieving the global target of eradicating Mother to child Transmission (MTCT) of HIV, the highest in the world [4]. The reason is not far-fetched since most of our mothers delivered outside the hospitals [5].

Implementation of PMTCT remains low at $30 \%$ as only about $4 \%$ of HIV exposed infants are tested for HIV in the first two months of life [6]. Several challenges hinder the PMTCT delivery in Nigeria. These arise from poor uptake of antenatal care

*Address correspondence to this author at the Department of Pediatrics, University of Calabar, Calabar, Nigeria; Tel: 08033429633;

E-mail: odyvenn04@yahoo.co.uk services and very low utilization of orthodox health care facilities for delivery resulting in low early infant diagnosis [7, 8]. In addition, a study in our centre has shown that mothers earlier screened and were all negative later seroconverted and delivered children with HIV infection. This is because repeat HIV screening is not routinely done at delivery. Inability to diagnose HIV infection as early as possible in infants and children severely limits access to antiretroviral therapy (ART). Surprisingly, mothers that deliver outside the hospital setting carry their children for immunization. Since immunization facilities are available in most communities in the country, this could be used for the early infant diagnosis of HIV [9]. Gladly, the six week immunization period which is the entrance to the National Programme on Immunization (NPI) has the highest coverage $[9,10]$. This is also coincides with when the mothers visit the health, facilities for their postnatal checks. If well harnessed, immunization centers can be used to increase PMTCT in Nigeria, a developing country where uptake of PMTCT is low.

The study was therefore conducted at immunization centers in Calabar to mop up infants with HIV to serve as portal for the prevention of HIV in infants. The results will help to formulate policies aimed at integrating immunization clinics as centers for the prevention and control of HIV. 


\section{SUBJECTS AND METHODS}

This cross sectional descriptive study was conducted among infants aged six to 14 weeks attending immunization clinics in Calabar, Nigeria. The study was carried out from $1^{\text {st }}$ August 2014 to $30^{\text {th }}$ September 2014.

Calabar as earlier described by Udo et al. [11] is made up of two Local Government Areas (LGAs) namely Calabar Municipality and Calabar South. Immunization centers were used for the study. Ethical committee of the University of Calabar Teaching Hospital, Calabar and Ministry of Health, Cross Rivers State, Nigeria approved the study. Children aged six to 14 weeks that made the inclusion criteria were recruited. Multistage sampling method was used to select 330 subjects from the 22 immunization centers using table of random numbers. Those excluded were ill infants and those who were HIV positive. Pretest counseling was done. A detailed history was obtained that included the child's biodata, past medical history, pregnancy and nutritional history (Exclusive Breast Feeding; Mixed feeding or formula) maternal HIV status, mode and place of delivery, history of use of Anti Retroviral Drugs(ARVs). General examination was conducted and anthropometry measured included Weight, Occipito Frontal Circumference (OFC) and length.

HIV testing was done on all infants-mother pair using Determine ${ }^{\text {TM }}$ HIV $1 / 2$ from ABBOT Medical Japan and HIV 1/2 STAT PAK ${ }^{T M}$ from CHEMBIO Diagnostic systems, Inc. USA. Post test counseling was done, and infants who were reactive had specimen collected for Dried Blood Spot (DBS) using DNA PCR according to the National guidelines for the diagnosis of Pediatric HIV [12]. Those that had positive DBS were enrolled into the treatment programme. All HIV positive mothers were treated. Refusal to participate in the study carried no penalty.

Data were recorded and standard statistical analysis was performed using SPSS statistical package version 20. Continuous variables were summarized using means, median and ranges as appropriate. Proportions were compared using Chi-square test of significance. A probability ( $P$-value) less than 0.05 was considered statistically significant.

\section{RESULTS}

A total of 330 infants aged 6 to 14 weeks were recruited into the study. Of these, $173(52.4 \%)$ were males while $157(47.6 \%)$ were females giving a male to female ratio of 1.1:1. Mean age of infants was $9.20 \pm$ 3.1 weeks. Majority of the infants $52.7 \%$ were aged $6-8$ weeks.

Table 1 shows age and sex distribution of the infants.

Twenty four out the 330 infants tested positive with rapid antibody test, but following confirmation with DNA PCR using the DBS 14 out of the 24 were infected. This gives a prevalence of $4.2 \%$.

Table 1: Age and Sex Distribution of Infants in the Study

\begin{tabular}{|c|c|c|}
\hline Variables & Frequency (N=330) & Percentage (\%) \\
\hline \hline Sex & 173 & 52.4 \\
\hline Male & 157 & 47.6 \\
\hline Female & $\mathbf{3 3 0}$ & $\mathbf{1 0 0}$ \\
\hline \multicolumn{2}{|c|}{} \\
\hline Age group in weeks & 174 & 52.7 \\
\hline $6-8$ & 41 & 12.4 \\
\hline $9-11$ & 115 & 34.9 \\
\hline $12-14$ & $\mathbf{3 3 0}$ & $\mathbf{1 0 0}$ \\
\hline
\end{tabular}

Four $(28.6 \%)$ were delivered to mothers who were previously negative. Nine did not know their HIV status during pregnancy and one took ARV less than two weeks before delivery. All the six that took ARV more than 2 weeks did not have HIV but were exposed.

Nine $(64.3 \%)$ of the mothers of the HIV infected infants booked for ANC. Out of the 14 HIV infected, only one $(7.1 \%)$ was delivered to a mother who was HIV positive during ANC but the mother commenced ARVs only two weeks before delivery. Antenatal registration and maternal HIV status were statistically significant $P=0.03$ and $P 0.02$ respectively. Ten infants $(71.4 \%)$ had mixed feeding, while $4(28.6 \%)$ were exclusively breastfed. No baby received only Breast Milk Substitute (BMS) Table 2.

\section{DISCUSSION}

The prevalence of HIV in this population was $4.2 \%$, including one infant whose mother started ARV less than 2 weeks before delivery. This is high considering the National prevalence of $3.4 \%$ [4]. It is almost similar to $5.3 \%$ earlier recorded in Calabar among infants of 
Table 2: Relationship between Ante natal Care (ANC) Characteristics and HIV Infection in Infants

\begin{tabular}{|c|c|c|c|c|c|}
\hline \multicolumn{6}{|c|}{ HIV STATUS OF INFANT(DNA PCR) } \\
\hline Variable & $\begin{array}{l}\text { Positive } \\
n=14(\%)\end{array}$ & $\begin{array}{l}\text { Negative } \\
\mathrm{n}=316(\%)\end{array}$ & $\begin{array}{c}\text { Total } \\
\mathrm{N}=330(\%)\end{array}$ & $x^{2}$ & P-value \\
\hline \multicolumn{6}{|l|}{ ANC Registration } \\
\hline Yes & $9(64.3)$ & $277(87.7)$ & $286(86.7)$ & \multirow[t]{3}{*}{ FET } & \multirow[t]{3}{*}{$0.03^{*}$} \\
\hline No & $5(35.7)$ & $39(12.3)$ & $44(13.3)$ & & \\
\hline Total & $14(100.0)$ & $316(100.0)$ & $330(100.0)$ & & \\
\hline \multicolumn{6}{|c|}{ Maternal ANC HIV status } \\
\hline Positive & $1(7.1)$ & $6(1.9)$ & $7(2.1)$ & \multirow[t]{4}{*}{ FET } & \multirow[t]{4}{*}{$0.02^{*}$} \\
\hline Negative & $4(28.6)$ & 195(61.7) & $199(60.3)$ & & \\
\hline Unknown & $9(64.3)$ & $115(36.4)$ & $124(37.6)$ & & \\
\hline Total & $14(100.0)$ & $316(100.0)$ & $330(100.0)$ & & \\
\hline \multicolumn{6}{|l|}{ Feeding options } \\
\hline EBF & $4(28.6)$ & $165(52.2)$ & $169(51.2)$ & \multirow[t]{4}{*}{ FET } & \multirow[t]{4}{*}{0.20} \\
\hline BMS & $0(0.0)$ & $7(2.2)$ & $7(2.1)$ & & \\
\hline Mixed & $10(71.4)$ & $144(45.6)$ & $154(46.7)$ & & \\
\hline Total & $14(100.0)$ & $316(100.0)$ & $330(100.0)$ & & \\
\hline \multicolumn{6}{|l|}{ Vaginal bleeding } \\
\hline Yes & $1(7.1)$ & $37(11.7)$ & $38(11.5)$ & \multirow[t]{3}{*}{ FET } & \multirow[t]{3}{*}{1.00} \\
\hline No & $13(92.9)$ & $279(88.3)$ & 292(88.5) & & \\
\hline Total & $14(100.0)$ & $316(100.0)$ & $330(100.0)$ & & \\
\hline \multicolumn{6}{|l|}{ Vaginal discharge } \\
\hline Yes & $3(21.4)$ & $65(20.6)$ & $68(20.6)$ & \multirow[t]{3}{*}{ FET } & \multirow[t]{3}{*}{1.00} \\
\hline No & 11(78.6) & $251(79.4)$ & $262(79.4)$ & & \\
\hline Total & $14(100.0)$ & $10(100.0)$ & $24(100.0)$ & & \\
\hline \multicolumn{6}{|c|}{ Maternal ARVs in pregnancy } \\
\hline Yes & $1(7.1 \%)$ & $5(50.0)$ & $6(25.0)$ & \multirow[t]{3}{*}{ FET } & \multirow[t]{3}{*}{0.05} \\
\hline No & $13(92.9 \%)$ & $5(50.0)$ & $18(75.0)$ & & \\
\hline Total & $14(100.0)$ & $10(100.0)$ & $24(100.0$ & & \\
\hline
\end{tabular}

*Statistically significant FET = Fisher's Exact Test.

mothers that tested negative during Antenatal care Udo et al. [11], this continuous to show the poor uptake of services at orthodox health care facilities in the sub region. Our findings is also similar to the study by Lamias et al. [13] in Pakistan that considered vertical transmission, however, much higher than the zero prevalence reported by Edathodu et al. [14] in Saudi Arabia. The lack of PMTCT intervention during ANC and delivery as many of the infected infants were delivered outside the orthodox health facilities where PMTCT services were not available may be responsible for the high prevalence when compared to other studies $[15,16]$.

Though, it would have been better to aim at zero MTCT of cases if mothers were diagnosed earlier, but this was not the case. Interestingly, all the infants that their mothers took ARVs more than two weeks prior to delivery did not have HIV but were exposed infants. Further intervention at this stage should be on going since mothers still practice mixed feeding that have been shown to increase MTCT of HIV. There may be initial rejection of integration of PMTCT into immunization centers but require strong advocacy and commitment.

It is of note that most HIV infected infants were asymptomatic and this may have led to the delay in diagnosis and treatment [17]. These numbers would be missed if HIV screening were not done; it is then recommended that immunization centers should be used to bridge the gap in the PMTCT. An integration of 
PMTCT to routine maternal, child and women health services has been supported by South Africa to reduce the high frequency of MTCT [17].

The practice of Exclusive Breast Feeding (EBF) has not significantly improved. The breastfeeding rate in Nigeria is $7.1 \%$ [18]. A recent study by Manji et al. [19] in Tanzania showed that EBF protected against MTCT of HIV through 12 months of age. The $85 \%$ transmission rate at 2 months however declined to less than $30 \%$ at 4 months. Though $28.6 \%$ of the infants received EBF in our study, it was not possible to exclude other predisposing factors responsible for the high levels of MTCT like the viral load, STIs and nutritional status of the mothers.

It was not surprising that majority of the mothers that practiced mixed feeding had their children infected with HIV. This is attributable to the breakdown of the integrity of the infants' protective gastrointestinal mucosal barrier.

Majority (57.2\%) of the babies were delivered outside orthodox health facilities. Attempts to train Traditional birth attendants to refer high risk cases have failed. The model in Ondo state, South West Nigeria is encouraging where each maternal death must be reported and investigated otherwise such facilities is shut down and personnel prosecuted. This should be adopted in the entire region in Nigeria.

Not all pregnant women are screened in Nigeria despite free screening practiced over the past 15 years, $37.6 \%$ of mothers did not know their HIV status. This is challenging to health care providers in Nigeria and measures must be put in place to address it. It will not be out of place if house to house screening is done. It might be tasking because precounseling need to be done, but if Provider Initiated Testing and Counseling (PITC) is applied it would increase the number tested. The $28.6 \%$ of infants that their mothers were negative would have been prevented if screening is done at least twice during pregnancy as suggested by Udo et al. [11].

\section{CONCLUSION}

This study shows that infants with HIV and those exposed are still been missed and only diagnosed later in life during immunization. Immunization centres should therefore be incorporated as screening points.

\section{RECOMMENDATION}

It is hereby recommended that measures be put in place to use immunization centers to screen infants after pretest counseling. Those found to be seropostive should be referred to centers with facilities for further evaluation and management.

\section{ACKNOWLEDGEMENTS}

The authors would like to acknowledge the contributions of the Doctors, Nurses and other staff of the facilities used for this study. Our gratitude also goes to the Ministry of Health, Cross River State, Nigeria for their permission to use the health facilities.

\section{CONFLICT OF INTEREST}

None.

\section{FUNDING}

None.

\section{REFERENCES}

[1] Tindyebwa D, Kayita J, Musoke $\mathrm{P}$, Eley B, Nduati $\mathrm{R}$ Tumwesigye N, et al., Eds. Handbook of Paediatric AIDS in Africa. $2^{\text {nd }}$ ed. Kampala: ANECCA 2011; pp. 3-33.

[2] Liu L, Oza S, Hogan D, et al. Global, regional, and national causes of child mortality in 2000-13, with projections to inform post-2015 priorities: an updated systematic analysis. Lancet 2015; 385: 430-40. http://dx.doi.org/10.1016/S0140-6736(14)61698-6

[3] Fapohunda BM, Orobaton NG. When women deliver with no one present in Nigeria: who, what, where and so what? Plos One 2013; 8: e69569.

http://dx.doi.org/10.1371/journal.pone.0069569

[4] Federal Republic of Nigeria. Global AIDS response progress report, Nigeria. Abuja: National action committee on AIDS 2014; P33-8.

[5] Sinunu MA, Schouten EJ, Wadonda-Kabondo N, et al. Evaluating the impact of prevention of mother-to-child transmission of HIV in Malawi through immunization clinicbased surveillance. PLoS One 2014; 9: e100741.

[6] Burr CK, Lampe MA, Corle S, et al. An end to perinatal HIV: Success in the US requires ongoing and innovative efforts that should expand globally. J Public Health Policy 2007; 28 : 249-60.

http://dx.doi.org/10.1057/palgrave.jphp.3200126

[7] Okeudo C, Ezem B, Ojiyi E. Mother-to-child transmission rate of HIV at orlu, south-eastern Nigeria. Int J Gyneco Obstet 2012; 16: 2 .

[8] Bloemen S. Early infant HIV diagnosis helps save lives in Malawi. Available via unicef.org/infobycountry/malawi 46696.html. 2013.

[9] National Bureau of Statistics. Multiple indicator cluster Survey Report 2013: monitoring the situation of children. Abuja: National Bureau of Statistics 2013; pp. 48-51.

[10] Sadoh AE, Eregie C. Timeliness and completing rate of immunization among Nigerian children attending clinic based immunization service. J Health Popul Nutr 2009; 27: 391-5. http://dx.doi.org/10.3329/jhpn.v27i3.3381

[11] Udo JJ, Ntia HU, Anah MU, Eyong KI, Ewa AU, Etuk IS. HIV seroprevalence in children whose mothers were seronegative at antenatal care booking in an immunization centre in Calabar, Nigeria. Pediatr Infect Dis J 2013; 8: 83-6. 
[12] Federal Ministry of Health Nigeria. Integrated National guidelines for HIV prevention, treatment and care. Abuja: Federal Ministry of health Nigeria 2014; pp. 20-32.

[13] Lamias MJ. Maternal and Perinatal risk factors associated with vertical transmission of hiv-1 infection from mother to child. Am J Trop Hyg 2014; 90: 902-7.

[14] Edathodu J, Halim MM, Dahham MB, Alrajhi AA. Mother-tochild transmission of HIV: experience at a referral hospital in Saudi Arabia. Ann Saudi Med 2010; 30: 15-7.

[15] Berhan, Z., Abebe, F., Gedefaw, M, Tesfa, M. Prevalence of HIV and associated factors among infants born to HIV positive women in Amhara region, Ethiopia. Int $\mathrm{J}$ Clin Med 2014; 5: 464-74.

http://dx.doi.org/10.4236/ijem.2014.58065

[16] Bucagu M, Muganda J. Implementing primary health care based PMTCT interventions: Operational perspectives from
Muhima cohort analysis (Rwanda). Pan Afr Med J 2014; 18 : 59.

http://dx.doi.org/10.11604/pamj.2014.18.59.3895

[17] Horwood C, Haskins L, Vermaak K, Phakathi S, Subbaye R Doherty T. Prevention of mother to child transmission of HIV programme in KwaZulu-Natal, South Africa: an evaluation of PMTCT implementation and integration into routine maternal, child and women's health services. Trop Med Int Health 2010; 15: 992-9.

http://dx.doi.org/10.1111/j.1365-3156.2010.02576.x

[18] Nigeria Demographic Health Survey. National Population Commission, Federal Republic of Nigeria. ICF International Rockville, Maryland, USA 2014.

[19] Manji KP, Dugann C, Liu E, et al. Exclusive Breast feeding protects against MTCT of HIV though 12 months of age in Tanzania. J Trop Paediatr 2016. 